\title{
Engineering of Plants for Efficient Production of Therapeutics
}

\author{
Lini Sethi ${ }^{1,2} \cdot$ Khushbu Kumari $^{1,2} \cdot{\text { Nrisingha } \text { Dey }^{1}}^{(1)}$ \\ Received: 24 June 2021 / Accepted: 10 August 2021 / Published online: 16 August 2021 \\ (c) The Author(s), under exclusive licence to Springer Science+Business Media, LLC, part of Springer Nature 2021
}

\begin{abstract}
Plants are becoming useful platforms for recombinant protein production at present time. With the advancement of efficient molecular tools of genomics, proteomics, plants are now being used as a biofactory for production of different life saving therapeutics. Plant-based biofactory is an established production system with the benefits of cost-effectiveness, high scalability, rapid production, enabling post-translational modification, and being devoid of harmful pathogens contamination. This review introduces the main challenges faced by plant expression system: post-translational modifications, protein stability, biosafety concern and regulation. It also summarizes essential factors to be considered in engineering plants, including plant expression system, promoter, post-translational modification, codon optimization, and fusion tags, protein stabilization and purification, subcellular targeting, and making vaccines in an edible way. This review will be beneficial and informative to scholars and readers in the field of plant biotechnology.
\end{abstract}

Keywords Plant expression system $\cdot$ Edible vaccine $\cdot$ Subcellular targeting $\cdot$ Post-translational modification . Glycoengineering $\cdot$ Protein purification

$\begin{array}{ll}\text { Abbreviations } \\ \text { CHO } & \text { Chinese hamster ovary } \\ \text { AIDS } & \text { Acquired immune deficiency syndrome } \\ \text { WHO } & \text { World Health Organization } \\ \text { T-DNA } & \text { Transfer DNA } \\ \text { CaMV 35S } & \text { Cauliflower mosaic virus 35S promoter } \\ \text { CP } & \text { Core promoter } \\ \text { UAS } & \text { Upstream activating sequence } \\ \text { UTR } & \text { Untranslated region } \\ \text { GalT } & \beta-1,4 \text { Galactosyltransferase } \\ \text { TFs } & \text { Transcription factors } \\ \text { ZF-TFs } & \text { Zinc finger transcription factors }\end{array}$

Nrisingha Dey

ndey@ils.res.in; nrisinghad@gmail.com

Lini Sethi

linisethi@gmail.com

Khushbu Kumari

khusikumari357@gmail.com

1 Division of Plant and Microbial Biotechnology, Institute of Life Sciences, NALCO Square, Chandrasekharpur, Bhubaneswar, Odisha 751023, India

2 Regional Centre for Biotechnology, National Capital Region Biotech Science Cluster, Faridabad, Haryana (NCR Delhi) 121001, India
TALE-TFs Transcription activator-like effector transcription factors

ELP Elastin like partners

HFBI Hydrophobin

ITC Inverse transition cycling

SAR/MAR Matrix association region/scaffold attachment region

APC Antigen-presenting cells

ER Endoplasmic reticulum

PSVs Protein storage vacuoles

GCB Glucocerebrosidase

IF Plant interstitial fluid

COVID-19 Coronavirus Disease 2019

VIGS Virus-induced gene silencing

RNAi RNA interference

\section{Introduction}

The growing needs in every field demand mass production of the desired product with minimal inputs. Likewise, the increasing demand for various pharmaceuticals has brought us to switch to a more efficient system, i.e., plants. Plants have been cultivated for ages to fulfill our basic needs majorly. But with the progress in genomics, proteomics, and metabolomics, plants are now being used as factories for the 
production of desired proteins, pharmaceuticals, vaccines, industrial enzymes, etc. They are the most cost-effective systems for the production of recombinant proteins. Various factors are considered before choosing a system, such as a cost-effectiveness, product safety, storage conditions, purification process, environmental concerns, and acceptance by the public. Unlike mammals, plants have a natural barrier against the ingression of a mammalian pathogen. Moreover, plant infecting viruses cannot infect during plant cell cultures by providing restrictions via plasmodesmata that restrict the route of virus movement [1].

In some cases, plants also require similar cultivation procedures as mammalian cell cultures, for example, plant tissue culture of hairy roots and aquatic plants; suspension culture of plant cells [2]. However, these require the same scale-up cost as $\mathrm{CHO}$ cells like fermenters but need basic nutrient requirements and ease the downstream purification as it lacks mammalian pathogen contamination. Increasing demand for biomedicines has been linked with expensiveness and ineffectiveness of the current production strategies such as yeast, bacteria, and animal cell culture with transgenic animals [3-5]. In contrast, plants have the upper hand as a production system for desired recombinant protein at a large scale in terms of safety concern, applicability, and cost-effectiveness.

Two important plant-based expression strategies (transient and transgenic) minimize the production cost compared to others. The transient strategy in plants via vacuum infiltration with Agrobacterium tumefaciens transformed with a plant expression vector harboring desired protein encoding gene [6]. However, this technique is fast but requires continuous infiltration of transformed agrobacterium, coinciding with the same production cost as fermentation. In contrast, the transgenic methods are cost-effective, in which seed banks can be established and used in continuous batches without any manipulation [7]. Thus, transgenic plants are most advantageous among others in the large-scale production of the desired protein. Majorly the three techniques to cultivate such plants: in a conventional greenhouse, in vertical farming units, and under an open field environment. Virtually open fields provide unlimited large-scale production but lack containment, so unsuitable for the production of pharmaceutical transgenes [8].

\section{Limitations of Expression Systems}

With the advent of recombinant DNA technology, many model systems such as bacteria, fungi, insect cells, mammalian cells, and whole animal are being used to produce biologics such as therapeutic proteins for the treatment of various diseases such as diabetes, AIDS. All the systems have their limitations and studies have found that plant-based system overcomes most of them. Relying on prokaryotic systems for protein production is inefficient as they lack organelles for protein processing, such as post-translational modifications resulting in misfolded proteins [9]. Also, they produce endotoxins and pyrogenes, which adds an additional step in purification leading to less quantity of desired protein, and chances of degradation remains high. Insoluble protein accumulation has been found in regards to large protein overexpression in bacterial systems.

Eukaryotic systems such as fungi have been widely used to overcome the limitations of the prokaryotic system, but it has been found that during large-scale production, the yield decreases [10]. They have differences in N \& O-linked oligosaccharides structures compared to mammals [9-11]. On the other hand, the insect system produces improperly processed proteins due to inefficient internal cleavage at arginine or lysine-rich regions [9]. Apart from them, the mammalian systems have a high maintenance requirement, complex nutrient media, ample production time, increased chances of contamination, etc. [12]. Many animals such as goat, rabbit, sheep, and others have been employed to produce therapeutics such as a1-antitrypsin. The production of recombinant proteins in the whole animal system is complex and laborious. Also, transgenic animals are susceptible to human pathogens, thus, limiting their effectiveness $[13,14]$.

The general methods employed for production of plantderived biologics is shown in Fig. 1.

Comparatively, engineered transgenic plants are potentially beneficial than others in the production of biologics.

- Cost-effective production of agricultural product on a larger scale, and use of edible parts of the plant to avoid purification procedure.

- Devoid of capitalization costs related to fermentation

- Proper eukaryotic assembly of multimeric proteins (antibodies); not possible in the case of bacteria.

- Comprehensive scale-up production with enhanced biosafety concern, as plants do not serve as hosts for human pathogens [15-19].

- Do not have oncogenic DNA sequences and endotoxins, hence safe expression system.

- Can be modified to express in various organelles like in chloroplast, where high expression is noted.

\section{Challenges Faced by Plant Expression System}

Though the use of plant system has brought many benefits to society as it overcomes the limitations imposed by other systems. However, it also comes with certain challenges and concerns that need to be resolved for an efficient and safe system for biologics production. 


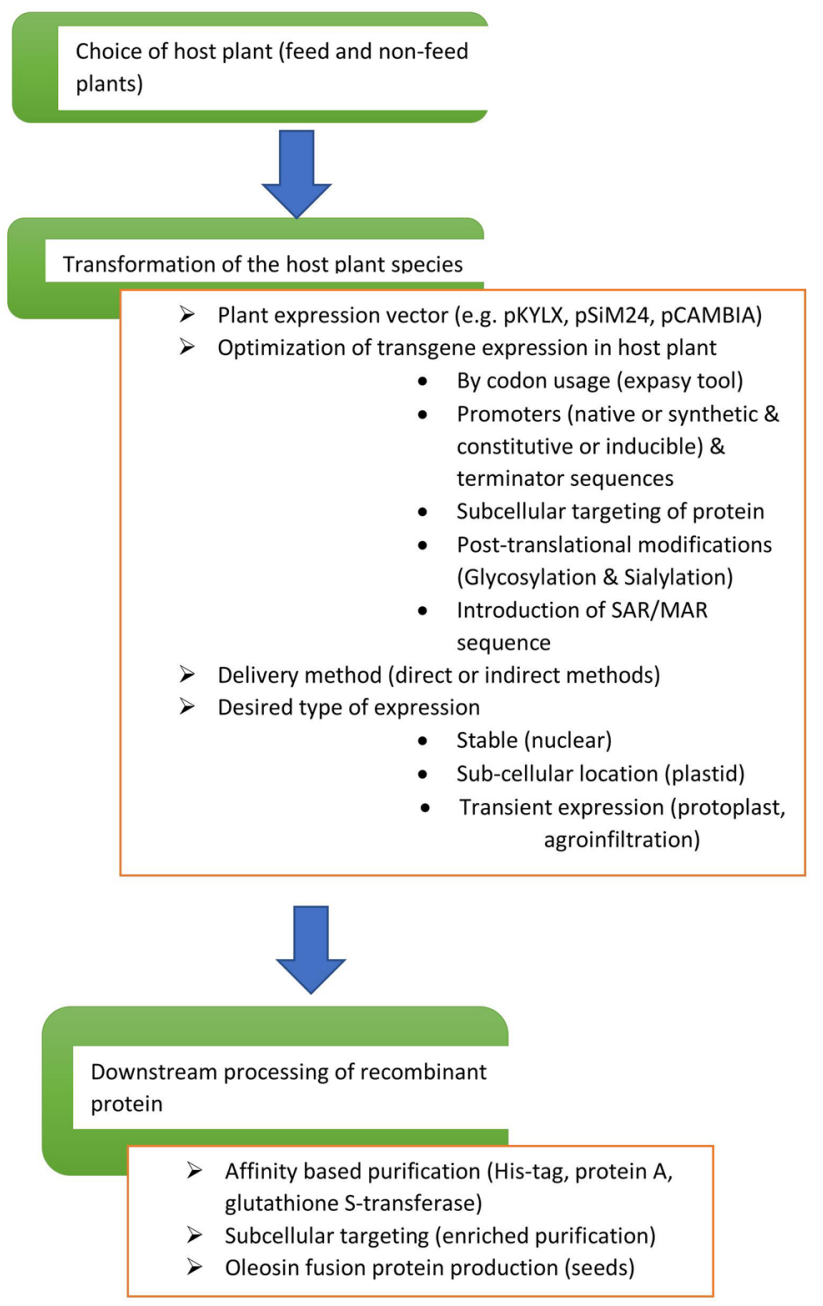

Fig. 1 Schematic representation for the development of plant-based biologics

\section{Post-translational Modifications}

One of the most important challenge in plant-based expression system is the differences in the nature of glycosylation which differs at some places compared to animals. There are differences in N-glycan composition in Golgi apparatus of plants compared to animals. In plants $\alpha 1-6$ fucose, glucose and sialic acid is absent instead they add $\alpha 1-3$ fucose and $\beta 1-2$ xylose [20]. The differences account for variability in the distribution of the product, changes in the half-life of the product in serum, changes in activity can be observed, followed by affecting the immunogenicity of the therapeutic proteins [21]. The human-like N-glycosylation is of utmost importance for producing therapeutic proteinlike monoclonal antibodies [22]. Hence, those therapeutic proteins which do not require such modifications can be well suited for production.

\section{Protein Stability}

This also remains the question of how much stable the protein inside the plant body would be, which is essential for its action and mainly depends on the expression system. It varies from plant to plant. Some foods need to be cooked for consumption which would simultaneously cause denaturation of the protein. Some strategies employed to preserve the expressed protein are freeze-drying the plant and using chloroplast expression for proteins that do not require glycosylation [23].

\section{Biosafety Concerns}

There are many benefits of genetically modified plantderived biologics, but the public is very reluctant to consume them. There is many biosafety, ethical, moral, and environmental concerns associated with it that bring many challenges to be overcome. Initial studies have found that genetically modified plant-derived biologics are safe for consumption and are also functional inside the body. But the differences in post-translational modifications raise questions as it is not yet clarified. Apart from that, the efficacy and effects of immunological response to repeated exposure to oral consumption of plant-derived vaccines would be observed or not. The next concern is its release into the environment that can lead to inadvertence entry into the food chain. To restrict gene flow, many strategies have been adopted, such as; (1) use of glasshouses, (2) to overcome pollen outflow, use of male sterile plants is preferred, (3) employment of terminator technology, (4) use of tissuespecific promoters and inducible promoters to prevent the adverse effects on plants, (5) using self-pollinating plants such as wheat, rice (6) chloroplast transformation technology also restricts pollen-mediated gene flow [24-26]. Many plant edible vaccines are still in phase I clinical trials, and to date, there is no vaccine approved to be released in the market. The variation in dosage from plant to plant and from generation to generation is a major concern.

\section{Regulatory Approval}

As this technology holds promising results, drug companies are still reluctant to invest huge sums of money in approving new products by drug approval administrations as already accepted expression systems are available [27]. In conclusion, this economic constraint and chances of cross pollination and escape of gene through plant debris traveling in air or other ways may affect wildlife, and nearby populations limit the scale of progress and acceptance of this new technology. WHO concluded in a meeting held in Jan 2005 that the guidelines followed for the development, evaluation, and use of vaccines for edible vaccine would be similar to that 
of the conventional vaccine [28]. Due to a lack of awareness and the spread of myths, people are hesitant to accept genetically modified plants. If public acceptance is absent, then improvisation of this technology wouldn't be futile. The next issue is allergic reactions upon consumption of transgene, which may provoke hypersensitive reactions. The chances of cross-contamination between genetically modified and nongenetically modified plants is another issue. Also, release in water bodies would be a problem for the wildlife and population residing nearby. All these need to be monitored; otherwise, the consequences would raise serious complications $[29,30]$.

\section{Engineering Plants for a Suitable Production System}

\section{Plant Expression System}

The plant system to be employed wholly relies on producing stable transgenic plants and the transformed tissues specifically selected for cell culture. There are three methods utilized in plant transformation: (1) Agrobacterium-mediated transformation is used to integrate transgene sequences into the nuclear genome of the plant cells; (2) the biolistic approach used for transient transformation into the plastids; and (3) Recombinant plant viral vectors incubation with host explants. A transient expression of the recombinant gene in infected plant leaves was employed in this method [31]. But many other factors also matter, such as specific tissue to be used for transformation, targeted encoded gene to be expressed, post-translational processing, and the probable contamination with unsafe metabolites. Despite that, the selection of host species and production system is primarily influenced by the production costs inherent to the recovery of the recombinant protein. Several factors are essential, such as plant regeneration system, time and setup costs for transformation; scale-up and maintenance costs related to transgenic development; the cost associated with biomass production of the transgenic plant; costs needed for extraction, purification, and characterization; costs required for containment and storage of transgenic crop including its commercialization [32]. Diagrammatic representation of plant expression system and process for various biologics production is shown in Fig. 2.

Although transgenic plants produce stable folded and functional recombinant protein in plants, but for instant large production can be possible by transient expression via agroinfiltration or viral vector infection. In viral-based vector expression, the viral coat protein can be replaced by a gene of interest. It is a low cost and rapid protein expression, but there are higher chances of viral contamination of nearby plants. Furthermore, Icon genetics company have developed a technology called 'Magnification' that utilized viral replicon within Agrobacterium T-DNA that harbor encoded transgene for high expression yield. More specifically, many plant-infecting viruses' promoters have been characterized and reported for efficient protein expression. They can be used for industrial and pharmaceuticals production, which is not only safe but also provide stable expression.

\section{Promoter as a Regulatory Tool}

Apart from an optimized expression vector, a strong promoter is required for expressing the recombinant gene in the plant system. The constitutive promoter has been considered a strong promoter, used in different expression vectors for ubiquitously expressing the targeted encoding gene, transcription factors, and bioactive compounds consistently throughout plant growth and development stages. Currently, native or endogenous promoters have certain limitations, such as low specificity and expression that enforces the demand for designing a synthetic promoter to overcome the lingering issue. In modern synthetic biology, a newly constructed synthetic promoter can drive transgenes with constitutive, inductive, or tissue-specific nature of expression [33-37]. Native promoters are larger in size (around $1 \mathrm{kbp}$ length) than constitutive viral promoters (e.g., CaMV 35S) extensively used in plant biotechnology. Designing synthetic promoters based on the arranging upstream activating sequence (UAS) containing cis-motifs of different promoters and core promoter $(\mathrm{CP})$ derived from diverse origins to control foreign gene expression spatially and temporally for genetic engineering. For the construction of synthetic promoters, correct core promoter with its elements such as TATA box region, GA elements, and the CAAT box along with 5' untranslated region (UTR) for driving desired and efficient expression and stability of the transgene in the host organism. However, the presence of cis-regulatory in the upstream plays a crucial role in driving the transgene. The absence of the requisite cis-element might lead to no expression or only minimal basal transcription $[38,39]$. Synthetic promoters perform a critical role in translational research through gene overexpression. It is challenging to find out potential cis-acting elements in plant promoters involved in the transcriptional function. In silico, designing minimal synthetic components for relative control of gene expression gives a similar expression level. Genetic engineering constructs novel synthetic promoters along with synthetic TFs that can replace the endogenous network by introducing new synthetic pathways and links into the plant. Synthetic promoters would be used against the expression of the Synthetic TFs gene. This nuclear protein/Synthetic TFs interact with DNA binding domains of different synthetic promoters and enhance the gene expression. Synthetic ZF-TFs, TALE-TFs, and dCas9-TFs were expressed using constitutive promoters 


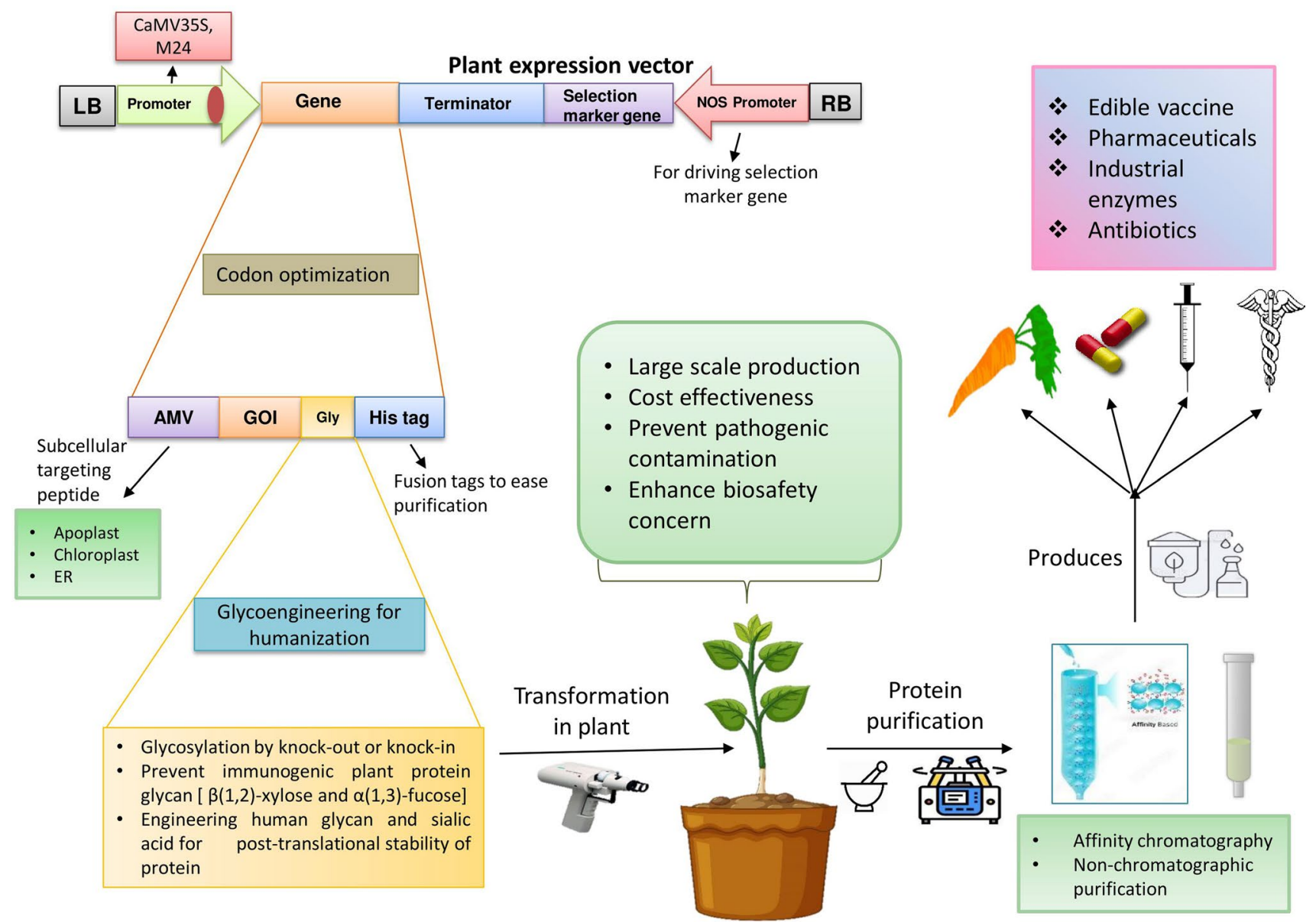

Fig. 2 Diagram of plant expression system and transformation approaches for recombinant protein production

CaMV35S and AtUBQ3 for transcriptional regulations of the endogenous gene[38]. New technologies for essential development in motif discovery, constructing and optimizing synthetic promoters, TFs designing, effector domain, and DNA binding domain will enhance synthetic promoters and TFs into plant genetic engineering.

Additionally, cis-elements are also essential segments found in the upstream region of a minimal promoter. A well-defined cis-acting element can enhance the promoter activity by altering the copy number of cis-acting elements influencing the level of transgene expression. Single copy number cis-acting element (Monomer) enhances gene activity by $1 \times$ time. Designing a specific cis-acting element by increasing copy numbers accelerated the gene expression $2 \times, 3 \times, 4 \times$ times, and so on for the presence of copy numbers $[40,41]$. Randomly arranged different cis-acting elements (Multimer) strengthen the stability of synthetic promoters. The copies of cis-acting elements in a synthetic promoter enhance that promoter's strength, action, and transcription rate. Following these strategies, we can generate a multimeric synthetic promoter by coupling differently characterized cis-elements as per the requirement for the targeted expression.

\section{Engineering Glycosylation and Sialylation for Humanization}

A prokaryotic expression system can be utilized for simple recombinant protein production that doesn't need further post-translation modification or does not glycosylate protein. Contrastingly, the eukaryotic expression system possesses glycosylation of protein, but some limitations exist because of the differences in the host system [42]. Like, hyper glycosylation occurs in the yeast but also most widely used mammalian cell culture and transgenic animals associated with human pathogen contamination, which is a significant concern for cost-effectiveness during purification, scalability, and ethical problems [43, 44]. These limitations demand a low cost and safer alternative for the production of therapeutics and industrial proteins. Pathway of protein synthesis is conserved among plants and animals. Still, there exists a difference in the post-translational modification in terms 
of glycan structure [45], besides similarities in producing the core high-mannose- type $N$-glycans, while differences in the structure of complex-type $\mathrm{N}$-glycans between plants and humans. Plant-based recombinant proteins possess exceptional $\beta(1,2)$-xylose and $\alpha(1,3)$-fucose that lacks in the mammalian system, which shows immunogenic response [46, 47]. Furthermore, plant-derived glycoprotein lacks terminal sialic acids and galactose residues, typically present in human proteins. The absence of sialic acid causes a very short life of recombinant protein in the human system. Resulting plant-derived system retaining its extensive utilization in the production of human biopharmaceuticals, as more than half of human proteins are glycoproteins and requires humanized post-translational modification [48].

The immunogenic response of plant glycan can be prevented by targeting the recombinant protein expression in ER. ER lumen-based platform for recombinant protein production possess high-mannose type $\mathrm{N}$-glycans similar to mammals, hence devoid of immunogenic complex plant glycans formation [49]. Mutant plant and glycosylation knock-out and knock-in can be utilized to prevent the immunogenic protein glycan formed by the plant-based system. Another glycogen engineering strategized by inactivating $\beta(1,2)$-xylosyl and $\alpha(1,3)$-fucosyltransferase or by co-expressing human $\beta-1,4$ galactosyltransferase (GalT) to make indistinguishable production like in mammal cell [50].

Human sialylation engineered in plant system to confer synthesis of sialic acid, essential monosaccharides required for cell signaling pathway and protein stability [51]. Approaches by the transient co-expression of human $\alpha 2,8$ polysialyltransferases or by introducing multigene harboring vector of human sialylation pathway, to synthesize polySia in plants [52]. Recent studies found that polySia (polymer of sialic acid) functions in multiple biological processes such as anti-inflammatory processes, neural regeneration, cell repair/ protection, and immunological processes [53, 54].

\section{Codon Optimization and Fusion Tags}

Codon optimization is used to facilitate heterologous gene expression and enhanced translational efficiency of a targeted gene, and it does so by accommodating codon bias of the specific host plant. The translational research's most important and foremost goal is to clone a particular gene or genomic fragment of interest. And procedures to uncharacterized genes start with DNA samples such as from eukaryotic genomic DNA. The next step is to obtain an extensive collection of clones via DNA library. As specific cloning vectors carry different sizes of DNA and size plays a crucial role in the successful ligation transformation. Plant expression vectors have certain size limitations in cloning targeted genes of interest. Codon usage varies from species to species and will affect the encoding recombinant protein expression level [55]. According to the data available for data usage for a given plant, specifically, lowest frequency transgene codon usage modified by nucleotide sequence without disturbing the encoding amino acid frame (hpl) [56]. SAR/ MAR sequences inclusion with the transgene enhances the transcriptional efficiency. It consists of 300-500 bp long ATrich DNA that organizes the genomic structure by interacting with a nuclear scaffold [57]. Many fusion proteins have been used to increase the accumulation, ease in purification, and protection against proteolysis. Plant proteases with recombinant protease inhibitors could enhance protein levels in transgenic without affecting the growth and development of plants. In plant system, several studies have shown protein stabilizing partners such as elastin like partners (ELP), Hydrophobins, oleosins, maize storage protein $\gamma$-zein (Zera), and ubiquitin-protein tags used to increase the accumulation of protein [58].

\section{Protein Stability and Purification}

Most of the protein purification is based upon the physiochemical properties of the recombinant protein, such as size, shape, charge, and hydrophobicity. Although chromatographic-based methods, including affinity chromatography, are most commonly used for protein purification, passthrough chromatographic resins are costly [59]. However, affinity-based chromatography is a benchtop laboratory tool with industrial use restricted to protein A chromatography for antibody production [60]. It is devoid of expensive resinbased chromatography and capable of purification in solution without using the chromatography process [61].

Many other non-chromatographic protein purification techniques have been introduced, specific to the plant system. The oleosin fusion protein is used to tag recombinant protein for its expression in oilseed plants [62]. Oleosin is a hydrophobic plant protein found to exist in the oil bodies of plant seeds. A Canadian biotechnology company SemBioSys expressed Oleosin fused human insulin in Arabidopsis [63]. Recently, this technology modified Oleosin-Protein expressed on the surface of oil bodies to affinity capture recombinant antibodies. ELP fused proteins have been used to increase the accumulation used in recombinant protein purification [64]. The advantage of ELP fused protein is being soluble at lower than their transition temperature and insoluble at above their transition temperature, thereby easing the solution's purification by inverse transition cycling (ITC). So the insoluble cellular protein can be removed below the transition temperature and heated above the transition temperature to capture the ELP fused protein. ELP consists of 30 pentapeptides repeats, and the transition temperature of the fusion protein depends upon the size, concentration, hydrophobicity, and ionic strength of the fusion partner in an aqueous solution [64]. Like ELP, another 
hydrophobic protein HFBI is also used as a fusion partner for the recombinant protein expression in plants. HFBI is amphiphilic and as a fusion protein, can be purified through an aqueous two-phase separation system with purification efficiency have been reported [65].

\section{Subcellular Targeting for Efficient Purification}

In plant cells, targeted foreign proteins can be localized into subcellular compartments such as apoplast, chloroplast, endoplasmic reticulum, mitochondria, and secretory pathways. Additional genes without the signal sequence can lead the expressed protein to accumulate in the cytoplasm, where protease presence can degrade the protein. Many signal sequences have been identified; their fusion with the transgene can localize the expressed protein to the membrane-bound organelles to limit the chance of proteolytic degradation. Such sequences like KDEL (Lys-Asp-Glu-Leu) and HDEL (His-Asp-Glu-Leu), are used to lead the recombinant protein into the endoplasmic reticulum (ER). Inside the $\mathrm{ER}$, protein is protected from protease degradation and the presence of chaperone proteins supports folding and assembling foreign proteins in the embedded environment and modifying the protein for post-translational glycosylation [56, 66, 67]. Contrastingly, when seeds are utilized as the storage site for protein accumulation, protein storage vacuoles (PSVs) are an appropriate subcellular compartment. A targeted recombinant protein can be targeted through the plant secretion pathway to extracellular space called apoplast, which can accumulate dissolved proteins in the aqueous phase. A biopharmaceutical protein gene, human Glucocerebrosidase (GCB) was synthesized to enriched in plant interstitial fluid (IF)/apoplastic fluid, useful for efficient biopharming [68].

Unlike other eukaryotic expression systems, the chloroplast system harboring recombinant protein doesn't go through the glycosylation pathway. Its post-translational modification system is not fully understood except for some essential processes such as disulphide bond formation, lipidation and phosphorylation [69]. This expression system provides large-scale production and cost-effective and suitable for simple protein production that doesn't require glycosylation and can be engineered for glycosylation at times of need in the future.

In plant, yield of protein is a significant concern, as high mRNA levels are not confirming the high levels of protein accumulation. One of the important concerns for producing heterologous protein is the presence of proteases responsible for degrading incorrectly or aberrant proteins. Several solutions have been reported to reduce the effect on recombinant proteins, including direct the expressed protein in specific membrane-bound organelles or the co-expression of protease inhibitors or the use of protein fusions [31]. Several factors regarding the subcellular location of expressed protein are essential, influencing the accumulation and the inherent environmental condition. Proteins can be expressed into tubers or seeds or in the edible part of the plant for the purpose of edible vaccine [70]. Inducible promoters can greatly influence the restriction of targeted protein expression to a certain time and inducible treatment and avoid the chance of undesired effect of recombinant protein on the host plant. Diverse approaches have been incorporated to enhance transgene expression, such as choice of strong promoters, dealing with copy numbers, increased efficiency of transcript activity and stability by transgene sequence optimization and protein accumulation increased by directing the expression to a specific tissue or using benefits of certain germplasm. Advances in the recombinant promoter or use of synthetic promoter not only control the expression of targeted protein and combination of mentioned other steps could enhance the expression of targeted protein with the good yields.

\section{Edible Vaccines}

Revolution in the field of genomics and proteomics has widened our knowledge to improve human health and control diseases. Novel techniques in molecular biology have brought forward ways to develop new treatments and vaccines to cure many diseases. Vaccines have been one of the greatest achievements in medical science. They have reduced the mortality rate to a great extent and even eradicated many deadliest diseases $[25,71]$. There was a time in the pre-vaccination era when half of the population was swept away due to smallpox, but when vaccines came, it was a boon to humankind as it cured many bacterial and viral diseases. Unfortunately, the development of new vaccines requires high capital, which remains the biggest obstruction for underprivileged countries apart from poor medical infrastructure and lack of implementation of healthcare policies acting as a constraint in vaccine development. Also, most vaccines require proper maintenance and delivery system; hence it becomes difficult for vaccines to reach a large part of the population. Consequently, this has challenged biotechnology to develop innovations that would be economically viable and have less complex storage requirements, and advantageous over existing conventional vaccines [72].

Recently a new concept emerging that can take over traditional vaccines is edible vaccines that combine medical science and plant biology. Plants can be used as bioreactors to produce a large amount of vaccines. Edible vaccines have emerged to contemplate the limitations of sophisticated traditional vaccines. They are easy to administer among all age groups, and no sophisticated maintenance requirements are needed. Many foods are being tested to produce vaccines, such as bananas, cucumber, carrots, potatoes. 
Currently, the live attenuated or inactivated strains of the pathogen are used for vaccination. These conventional vaccines consist of weakened forms of the pathogen, which may have the potential to multiply in the administered host. This little amount of virulence can also risk an immunocompromised patient or can be dangerous for some patients with different conditions causing severe illness. Other forms of vaccines, such as subunit vaccines, are better replacements than live attenuated vaccines. They consist of only some antigenic protein portions of the pathogen, which can elicit an immune response and help acquire immunological memory against the pathogen [73]. For the production of such vaccines, the antigen gene is transformed into the desired organism to express the gene. The living system chosen should be less dangerous to work in vitro, and the expressed protein could be easily purified and injected into patients. Currently, mammalian cells are being employed for subunit vaccine development, but the cell lines are difficult to maintain for larger yields apart from their requirement of complex media.

The upliftment in plant biotechnology in the past 15 years has made it possible to drive plants to produce edible vaccines. Edible plant vaccines would take down the requirements of large investments required to store and deliver conventional vaccines. The production of edible plant vaccines is almost similar to that of subunit vaccines. The gene encoding for a protein, i.e., antigen, capable of eliciting immunogenic response against the pathogen is incorporated into the selected plant genome through genetic engineering techniques. This process is called transformation, and the transformed plant is called a transgenic plant [74].

A plant-based vaccine was first attempted by Hiatt et al. in 1989 [75]. The transgenic plant will entail the properties of provoking an immune response against the pathogen. The selected plants should be such that they can be taken raw such as fruits like banana, or vegetables like tomato, cucumber, carrots. Edible vaccines are far better than traditional ones. They do not require sophisticated instruments for production; they are safer as they do not require administration through sterile injections or storage facilities. They stimulate mucosal responses as they are administered orally. This generates cell-mediated immunity, humoral immunity, and mucosal immunity. The vaccine taken orally is safe and not degraded by gastric enzymes because of the presence of the cell wall of the plant cell. When it passes through the intestine, the antigen is released at Payer's patches by the action of gut microflora [76]. The released antigen is taken up by M-cells and presented to B-cells with the help of APCs. This activates B-cells to secrete IgA class antibodies by differentiating into plasma cells, activating humoral and mucosal immunity. The cell-mediated immunity is also activated when T-cells help antibodies clear the antigen and provide protection by covering large areas by traveling to the lungs and nasal cavity through 'homing' receptors on mucosal membranes [77].

Advantages of plant edible vaccines:

- Capable of eliciting mucosal immunity, which is not observed through conventional vaccines.

- A safer way of immunization as they don't need a sterile injection and trained medical persons.

- No requirement of 'cold-chain' for storage which increases the cost of traditional vaccines. Plant edible vaccines can be stored in the form of seeds for years [78, 79].

- Easy for mass production, cost-effective as cultivation, harvesting, storage, and processing don't demand sophisticated instrumentation facilities.

- More stable as it can be stored at room temperature.

- It doesn't require adjuvants for eliciting an immune response.

- The purification process is omitted as direct ingestion of the modified plant is effective.

- No possibility of reverse virulence.

\section{Future Perspective}

Plants as bio-factories potentiate large-scale production of recombinant protein of industrial and pharmaceutical importance. Edible vaccines reduce the side effects caused by conventional vaccines and provide complete protection against harmful disease by activating the systemic and mucosal immune responses in the recipient body [80]. In 2020, the global biotechnology market was valued at $\$ 752.88$ billion and is expected to expand to approximately $15 \%$ from 2021 to 2028. In pharmaceutical manufacturing, the market size valued at $\$ 324.42$ billion in 2019 is predicted to increase to nearly $13 \%$ from 2020 to 2027 . The current scenario of a pandemic caused by COVID-19 has aggravated the involvement of the biotechnology industry, such as diagnostic companies, drug manufacturers, research laboratories, and multinational pharmaceutical companies, in developing therapeutic molecules for combating this viral infection. As the demand for therapeutics increases, plants are required as a cost-effective, safe, and efficient alternative for eukaryotic-based recombinant protein production. The lower yield of plant-based protein expression can be reduced by designing an efficient expression system and employing a suitable promoter to drive the transgene. Many companies have been developed that produce recombinant protein expression targeting valuable vaccines, industrial enzymes, and biopharmaceuticals. The list of plant-derived biologics and their clinical status is shown in Table 1. To avoid the impact of biosafety and environmental issues, plant-based manufacturing companies developed a containment zone to produce plant-based pharmaceuticals [93]. Additionally, 
Table 1 List of plant-derived recombinant products and their clinical trial status

\begin{tabular}{|c|c|c|c|c|}
\hline Product & Application & Host & Clinical trial status & References \\
\hline $\begin{array}{l}\text { Enterotoxigenic } \\
\text { E.coli LT-B }\end{array}$ & Diahrrea & Potato & Early phase I & {$[81]$} \\
\hline $\begin{array}{l}\text { Enterotoxigenic } \\
\text { E.coli LT-B }\end{array}$ & Diahrrea & Maize & Early phase I & {$[82]$} \\
\hline Norwalk virus $\mathrm{CP}$ & Diahrrea & Potato & Early phase I & {$[83]$} \\
\hline Rabies virus GP/NP & Rabies & Spinach & Early phase I & [84] \\
\hline HBV HBsAg & Hepatitis B & Lettuce & Early phase I & {$[85]$} \\
\hline HBV HBsAg & Hepatitis B & Potato & Phase I & {$[86]$} \\
\hline Vibrio cholera СТВ & Cholera & Rice & Phase I & {$[78]$} \\
\hline $\begin{array}{l}\text { Taliglucerase } \\
\text { alfa;Recombinant glu- } \\
\text { cocerebrosidase } \\
\text { (prGCD) }\end{array}$ & Gaucher disease & Carrot cell culture & $\begin{array}{l}\text { Phase } 3 \text { completed (2012); } \\
\text { FDA approved (2012) }\end{array}$ & https://clinicaltrials.gov \\
\hline ZMApp & Ebola virus & Tobacco & Phase 1 and 2 (2015) & https://clinicaltrials.gov \\
\hline PRX-102 & Fabry disease & Tobacco cell culture & Phase 1 and 2 (2014) & https://clinicaltrials.gov \\
\hline VaccinePfs 25 VLP & Malaria & Tobacco & Phase 1 (2015) & https://clinicaltrials.gov \\
\hline $\begin{array}{l}\text { Vaccine Recombinant pro- } \\
\text { tective antigen }\end{array}$ & Anthrax & Tobacco & Phase 1 (2014) & https://clinicaltrials.gov \\
\hline HAI-05 & H5N1 Vaccine & Tobacco & Phase 1 (2011) & https://clinicaltrials.gov \\
\hline $\begin{array}{l}\text { Recombinant human intrin- } \\
\text { sic factor }\end{array}$ & Vitamin B12 deficiency & Arabidop sis thaliana & Phase 2 completed (2006) & https://clinicaltrials.gov \\
\hline H5-VLP+ GLA-AF Vaccine & $\begin{array}{l}\text { Influenza A Subtype H5N1 } \\
\text { Infection }\end{array}$ & Tobacco & Phase 1 Completed (2014) & https://clinicaltrials.gov \\
\hline P2G12 IgG Antibody & HIV & Tobacco & Phase 1 completed (2011) & https://clinicaltrials.gov \\
\hline Influenza virus (H5N1) HA & Flu & Nicotiana benthami ana & Phase I & {$[87]$} \\
\hline Influenza virus (H1N1) HA & Flu & Nicotiana benthami ana & Phase I & {$[88]$} \\
\hline $\begin{array}{l}\text { Influenza virus(H7N9) HA } \\
\text { (H7; VLP) }\end{array}$ & Flu & $\begin{array}{l}\text { Nicotiana benthami } \\
\text { ana }\end{array}$ & Phase I & $\begin{array}{l}\text { Medicago Inc. (http://www. } \\
\text { medicago.com) }\end{array}$ \\
\hline LSBC scFVs & $\begin{array}{l}\text { Non-Hodgkin's } \\
\text { lymphoma }\end{array}$ & Tobacco & Phase I & [89] \\
\hline $\begin{array}{l}\text { CaroRX Guy’s } 13 \\
\text { SIgA }\end{array}$ & Dental caries & Tobacco & Phase II & {$[90]$} \\
\hline Gastric lipase & Cystic fibrosis, pancreatitis & maize & Phase II & http://www.meristem.com \\
\hline Human intrinsic factor & $\begin{array}{l}\text { Vitamin B12 } \\
\text { deficiency }\end{array}$ & Arabidop sis & Phase II & http://www.cobento.com \\
\hline Lactoferrin & Gastrointestinal infections & maize & Phase I & http://www.meristem.com \\
\hline Apo-A1 Milano & Cardiovascular disease & Safflowe $r$ & Preclinical & http://www.sembiosys.com \\
\hline Insulin (SBS-1000) & Diabetes & Safflowe $r$ & $\begin{array}{l}\text { Phase I/II completed Q1 } \\
2009\end{array}$ & [91] \\
\hline $\begin{array}{l}\text { Glucocerebrosidase } \\
\text { (UPLYSO) }\end{array}$ & Gaucher's disease & Carrot cell culture & Phase III trial completed & {$[92]$} \\
\hline $\begin{array}{l}\text { Alpha-galactosidase (PRX- } \\
\text { 102) }\end{array}$ & Fabry's disease & Carrot cell culture & Preclinical & Protalix \\
\hline $\begin{array}{l}\text { Acetylcholesterase (PRX- } \\
105)\end{array}$ & Biodefense & Carrot cell culture & Phase I (March 2010) & Protalix \\
\hline $\begin{array}{l}\text { Antitumor necrosis factor } \\
\text { (Pr-anti-TNF) }\end{array}$ & Arthritis & Carrot cell culture & Preclinical & Protalix \\
\hline$\beta$-Glucosidase & Gaucher's disease & Tobacco seeds & Preclinical & Plantechno srl \\
\hline $\begin{array}{l}\text { Interferon-alpha modified } \\
\text { release (Locteron R) }\end{array}$ & Hepatitis C & Lemna (Duckwe ed) & Phase II b & $\begin{array}{l}\text { Biolex therapeutics (Pitts- } \\
\text { boro, NC, USA) }\end{array}$ \\
\hline $\begin{array}{l}\text { Recombinant plasmin } \\
\text { (BLX-155) }\end{array}$ & Thrombosis prophylaxis & Lemna (Duckwe ed) & Preclinical & $\begin{array}{l}\text { Biolex therapeutics (Pitts- } \\
\text { boro, NC, USA) }\end{array}$ \\
\hline Anti-CD20 mAb (BLX-301) & Non-Hodgkin's lymphomas & Lemna (Duckwe ed) & Preclinical & Biolex Therapeutics \\
\hline
\end{tabular}


Table 1 (continued)

\begin{tabular}{|c|c|c|c|c|}
\hline Product & Application & Host & Clinical trial status & References \\
\hline Human serum albumin & $\begin{array}{l}\text { Maintenance of blood } \\
\text { plasma pressure }\end{array}$ & Flax & Preclinical & $\begin{array}{l}\text { Agragen (Cincinatti, OH, } \\
\text { USA) }\end{array}$ \\
\hline (RhinoRx) & Rhinovirus prophylactic & Tobacco & Phase II & $\begin{array}{l}\text { http://www.plantbiotechnol } \\
\text { ogy.com }\end{array}$ \\
\hline
\end{tabular}

tobacco use as a non-food and non-feed plant eliminates the risk of transgene contamination entering the food supply.

Engineering of plant expression system with humanized glycosylation and sialylation avoids immunogenic response in humans and enhances the short life of targeted protein. The industry advances towards the inexpensive, scalable, and efficient method to ease the purification and extraction from plant biomass. Many technological practices, such as CRISPR, RNA $i$, and other plant genomic techniques, has been incorporated along with designed synthetic promoter to revolutionize the field of plant biotechnology, enabling precise and targeted genome editing with the generation of industrial and pharmaceutical products. And advances in plant genomics, high-throughput platforms, and computational assistance, combined with the development of technologies such as virus-induced gene silencing (VIGS) and RNA interference (RNAi), have greatly accelerated potential for novel experimental design strategies [94].

\section{Declarations}

Conflict of interest The authors have no conflict of interest.

\section{References}

1. Raffaele, S., Bayer, E., Lafarge, D., Cluzet, S., Retana, S. G., Boubekeur, T., et al. (2009). Remorin, a solanaceae protein resident in membrane rafts and plasmodesmata, impairs potato virus X movement. The Plant Cell, 21(5), 1541-1555. https://doi.org/ 10.1105/tpc.108.064279

2. Xu, W., Yu, Y., Ding, J., Hua, Z., \& Wang, Y. (2010). Characterization of a novel stilbene synthase promoter involved in pathogenand stress-inducible expression from Chinese wild Vitis pseudoreticulata. Planta, 231(2), 475-487.

3. Knäblein, J. (2006). Plant-based expression of biopharmaceuticals. Encyclopedia of Molecular Cell Biology and Molecular Medicine. https://doi.org/10.1002/3527600906.mcb.200400120

4. Jones, D., Kroos, N., Anema, R., Van Montfort, B., Vooys, A., Van Der Kraats, S., et al. (2003). High-level expression of recombinant IgG in the human cell line PER.C6. Biotechnology Progress, 19(1), 163-168. https://doi.org/10.1021/bp025574h

5. Harvey, A. J., Speksnijder, G., Baugh, L. R., Morris, J. A., \& Ivarie, R. (2002). Expression of exogenous protein in the egg white of transgenic chickens. Nature Biotechnology, 20(4), 396399. https://doi.org/10.1038/nbt0402-396

6. Shoji, Y., Farrance, C. E., Bautista, J., Bi, H., Musiychuk, K., Horsey, A., et al. (2012). A plant-based system for rapid production of influenza vaccine antigens. Influenza and other Respiratory Viruses, 6(3), 204-210. https://doi.org/10.1111/j. 1750-2659.2011.00295.x

7. Sack, M., Hofbauer, A., Fischer, R., \& Stoger, E. (2015). The increasing value of plant-made proteins. Current Opinion in Biotechnology, 32(163), 170. https://doi.org/10.1016/j.copbio. 2014.12.008

8. Buyel, J. F. (2017). How plants can contribute to the supply of anticancer compounds. In S. Malik (Ed.), Biotechnology and production of anti-cancer compounds (pp. 39-72). Berlin: Springer.

9. Rai, M., \& Padh, H. (2001). Expression systems for production of heterologous proteins. Current Science, 80, 1121-1128.

10. Gerngross, T. U. (2004). Advances in the production of human therapeutic proteins in yeasts and filamentous fungi. Nature Biotechnology, 22(11), 1409-1414.

11. Cos, O., Ramón, R., Montesinos, J. L., \& Valero, F. (2006). Operational strategies, monitoring and control of heterologous protein production in the methylotrophic yeast Pichia pastoris under different promoters: A review. Microbial Cell factories, 5(1), 1-20.

12. Warner, T. G. (1999). Enhancing therapeutic glycoprotein production in Chinese hamster ovary cells by metabolic engineering endogenous gene control with antisense DNA and gene targeting. Glycobiology, 9(9), 841-850.

13. Echelard, Y., Ziomek, C. A., \& Meade, H. M. (2006). Production of recombinant therapeutic proteins in the milk of transgenic animals. BioPharm International, 19(8), 36-46.

14. Mahmoud, K. (2007). Recombinant protein production: Strategic technology and a vital research tool. Research Journal of Cell and Molecular Biology, 1(1), 9-22.

15. Larrick, J. W., \& Thomas, D. W. (2001). Producing proteins in transgenic plants and animals. Current Opinion in Biotechnology, 12(4), 411-418. https://doi.org/10.1016/S0958-1669(00)00236-6

16. Evangelista, R. L., Kusnadi, A. R., Howard, J. A., \& Nikolov, Z. L. (1998). Process and economic evaluation of the extraction and purification of recombinant $\beta$-glucuronidase from transgenic corn. Biotechnology Progress, 14(4), 607-614. https://doi.org/10.1021/ bp980047c

17. Giddings, G. (2001). Transgenic plants as protein factories. Current Opinion in Biotechnology, 12(5), 450-454.

18. Langridge, W. H. R. (2000). Edible vaccines. Scientific American, 283(3), 66-71.

19. Ponstein, A. S., Verwoerd, T. C., \& Mogen Nv, J. P. (1996). Production of enzymes for industrial use. Annals of the New York Academy of Sciences, 792(1), 91-98.

20. Obembe, O. O., Popoola, J. O., Leelavathi, S., \& Reddy, S. V. (2011). Advances in plant molecular farming. Biotechnology advances, 29(2), 210-222.

21. Twyman, R. M., Stoger, E., Schillberg, S., Christou, P., \& Fischer, R. (2003). Molecular farming in plants: Host systems and expression technology. TRENDS in Biotechnology, 21(12), 570-578.

22. Raju, T. S., Briggs, J. B., Borge, S. M., \& Jones, A. J. S. (2000). Species-specific variation in glycosylation of IgG: Evidence for the species-specific sialylation and branch-specific galactosylation and importance for engineering recombinant glycoprotein therapeutics. Glycobiology, 10(5), 477-486. 
23. Daniell, H., Kulis, M., \& Herzog, R. W. (2019). Plant cell-made protein antigens for induction of Oral tolerance. Biotechnology Advances, 37(7), 107413.

24. Mascia, P. N., \& Flavell, R. B. (2004). Safe and acceptable strategies for producing foreign molecules in plants. Current Opinion in Plant Biology, 7(2), 189-195.

25. Daniell, H., Streatfield, S. J., \& Wycoff, K. (2001). Medical molecular farming: Production of antibodies, biopharmaceuticals and edible vaccines in plants. Trends in plant science, 6(5), 219-226.

26. Warzecha, H., \& Mason, H. S. (2003). Benefits and risks of antibody and vaccine production in transgenic plants. Journal of Plant Physiology, 160(7), 755-764.

27. Rybicki, E. P. (2010). Plant-made vaccines for humans and animals. Plant Biotechnology Journal, 8(5), 620-637.

28. Van der Laan, J. W., Minor, P., Mahoney, R., Arntzen, C., Shin, J., Wood, D., \& \% J V. . (2006). WHO informal consultation on scientific basis for regulatory evaluation of candidate human vaccines from plants, Geneva, Switzerland, 24-25 January 2005. Vaccine, 24(20), 4271-4278.

29. Mishra, N., Gupta, P. N., Khatri, K., Goyal, A. K., \& Vyas, S. P. (2008). Edible vaccines: A new approach to oral immunization. Indian Journal of Biotechnology, 07, 283.

30. Sharma, M., \& Sood, B. (2011). A banana or a syringe: Journey to edible vaccines. World Journal of Microbiology and Biotechnology, 27(3), 471-477.

31. Streatfield, S. J. (2007). Approaches to achieve high-level heterologous protein production in plants. Plant biotechnology Journal, 5(1), 2-15.

32. Schillberg, S., Twyman, R. M., \& Fischer, R. (2005). Opportunities for recombinant antigen and antibody expression in transgenic plants-Technology assessment. Vaccine, 23(15), 1764-1769.

33. Chaturvedi, C. P., Sawant, S. V., Kiran, K., Mehrotra, R., Lodhi, N., Ansari, S. A., \& Tuli, R. (2006). Analysis of polarity in the expression from a multifactorial bidirectional promoter designed for high-level expression of transgenes in plants. Journal of Biotechnology, 123(1), 1-12.

34. Hou, L., Chen, L., Wang, J., Xu, D., Dai, L., Zhang, H., \& Zhao, Y. (2012). Construction of stress responsive synthetic promoters and analysis of their activity in transgenic Arabidopsis thaliana. Plant Molecular Biology Reporter, 30(6), 1496-1506.

35. Dey, N., Sarkar, S., Acharya, S., \& Maiti, I. B. (2015). Synthetic promoters in planta. Planta, 242(5), 1077-1094.

36. Xu, W., Yu, Y., Ding, J., Hua, Z., \& Wang, Y. (2010). Characterization of a novel stilbene synthase promoter involved in pathogen- and stress-inducible expression from Chinese wild Vitis pseudoreticulata. Planta, 231(2), 475-487. https://doi.org/ 10.1007/s00425-009-1062-8

37. Kumar, D., Patro, S., Ghosh, J., Das, A., Maiti, I. B., \& Dey, N. (2012). Development of a salicylic acid inducible minimal sub-genomic transcript promoter from Figwort mosaic virus with enhanced root-and leaf-activity using TGACG motif rearrangement. Gene, 503(1), 36-47.

38. Liu, W., \& Stewart, C. N., Jr. (2016). Plant synthetic promoters and transcription factors. Current Opinion in Biotechnology, 37, $36-44$.

39. Srivastava, R., Rai, K. M., Srivastava, M., Kumar, V., Pandey, B., Singh, S. P., et al. (2014). Distinct role of core promoter architecture in regulation of light-mediated responses in plant genes. Molecular Plant, 7(4), 626-641.

40. Rushton, P. J., Reinstädler, A., Lipka, V., Lippok, B., \& Somssich, I. E. (2002). Synthetic plant promoters containing defined regulatory elements provide novel insights into pathogen-and wound-induced signaling. The Plant Cell, 14(4), 749-762.
41. Gurr, S. J., \& Rushton, P. J. (2005). Engineering plants with increased disease resistance: How are we going to express it? TRENDS in Biotechnology, 23(6), 283-290.

42. Aricescu, A. R., Lu, W., \& Jones, E. Y. (2006). A time-and costefficient system for high-level protein production in mammalian cells. Acta Crystallographica Section D: Biological Crystallography, 62(10), 1243-1250.

43. Grillberger, L., Kreil, T. R., Nasr, S., \& Reiter, M. (2009). Emerging trends in plasma-free manufacturing of recombinant protein therapeutics expressed in mammalian cells. Biotechnology Journal, 4(2), 186-201.

44. Conde, R., Cueva, R., Pablo, G., Polaina, J., \& Larriba, G. (2004). A search for hyperglycosylation signals in yeast glycoproteins. Journal of Biological Chemistry, 279(42), 43789-43798.

45. Tekoah, Y., Ko, K., Koprowski, H., Harvey, D. J., Wormald, M. R., Dwek, R. A., \& Rudd, P. M. (2004). Controlled glycosylation of therapeutic antibodies in plants. Archives of Biochemistry and Biophysics, 426(2), 266-278.

46. Bardor, M., Faveeuw, C., Fitchette, A.-C., Gilbert, D., Galas, L., Trottein, F., et al. (2003). Immunoreactivity in mammals of two typical plant glyco-epitopes, core $\alpha(1,3)$-fucose and core xylose. Glycobiology, 13(6), 427-434.

47. Paccalet, T., Bardor, M., Rihouey, C., Delmas, F., Chevalier, C., D'Aoust, M., et al. (2007). Engineering of a sialic acid synthesis pathway in transgenic plants by expression of bacterial Neu5Acsynthesizing enzymes. Plant Biotechnology Journal, 5(1), 16-25.

48. Saint-Jore-Dupas, C., Faye, L., \& Gomord, V. (2007). From planta to pharma with glycosylation in the toolbox. TRENDS in Biotechnology, 25(7), 317-323.

49. Sriraman, R., Bardor, M., Sack, M., Vaquero, C., Faye, L., Fischer, R., et al. (2004). Recombinant anti-hCG antibodies retained in the endoplasmic reticulum of transformed plants lack core-xylose and core- $\alpha$ (1, 3)-fucose residues. Plant biotechnology Journal, 2(4), 279-287.

50. Bakker, H., Rouwendal, G. J. A., Karnoup, A. S., Florack, D. E. A., Stoopen, G. M., Helsper, J. P. F. G., et al. (2006). An antibody produced in tobacco expressing a hybrid $\beta$-1, 4-galactosyltransferase is essentially devoid of plant carbohydrate epitopes. Proceedings of the National Academy of Sciences USA, 103(20), 7577-7582.

51. Takeuchi, M., Inoue, N., Strickland, T. W., Kubota, M., Wada, M., Shimizu, R., et al. (1989). Relationship between sugar chain structure and biological activity of recombinant human erythropoietin produced in Chinese hamster ovary cells. Proceedings of the National Academy of Sciences USA, 86(20), 7819-7822.

52. Kallolimath, S., Castilho, A., Strasser, R., Grünwald-Gruber, C., Altmann, F., Strubl, S., et al. (2016). Engineering of complex protein sialylation in plants. Proceedings of the National Academy of Sciences USA, 113(34), 9498-9503.

53. Shahraz, A., Kopatz, J., Mathy, R., Kappler, J., Winter, D., Kapoor, S., et al. (2015). Anti-inflammatory activity of low molecular weight polysialic acid on human macrophages. Scientific Reports, 5(1), 1-17.

54. Kiermaier, E., Moussion, C., Veldkamp, C. T., Gerardy-Schahn, R., De Vries, I., Williams, L. G., et al. (2016). Polysialylation controls dendritic cell trafficking by regulating chemokine recognition. Science, 351(6269), 186-190.

55. Lessard, P. A., Kulaveerasingam, H., York, G. M., Strong, A., \& Sinskey, A. J. (2002). Manipulating gene expression for the metabolic engineering of plants. Metabolic Engineering, 4(1), 67-79.

56. Desai, P. N., Shrivastava, N., \& Padh, H. (2010). Production of heterologous proteins in plants: Strategies for optimal expression. Biotechnology advances, 28(4), 427-435.

57. Allen, G. C., Spiker, S., \& Thompson, W. F. (2000). Use of matrix attachment regions (MARs) to minimize transgene silencing. Plant Gene Silencing, 43, 241-256. 
58. Ahmad, A., Pereira, O. E., Conley, J. A., Richman, S. A., \& Menassa, R. (2010). Green biofactories: Recombinant protein production in plants. Recent Patents on Biotechnology, 4(3), 242-259.

59. Terpe, K. (2003). Overview of tag protein fusions: From molecular and biochemical fundamentals to commercial systems. Applied Microbiology and Biotechnology, 60(5), 523-533.

60. Chow, D., Nunalee, M. L., Lim, D. W., Simnick, A. J., \& Chilkoti, A. (2008). Peptide-based biopolymers in biomedicine and biotechnology. Materials Science and Engineering: R: Reports, 62(4), $125-155$

61. Joensuu, J. J., Conley, A. J., Lienemann, M., Brandle, J. E., Linder, M. B., \& Menassa, R. (2010). Hydrophobin fusions for high-level transient protein expression and purification in Nicotiana benthamiana. Plant Physiology, 152(2), 622-633.

62. Capuano, F., Beaudoin, F., Napier, J. A., \& Shewry, P. R. (2007). Properties and exploitation of oleosins. Biotechnology Advances, 25(2), 203-206.

63. Nykiforuk, C. L., Boothe, J. G., Murray, E. W., Keon, R. G., Goren, H. J., Markley, N. A., \& Moloney, M. M. (2006). Transgenic expression and recovery of biologically active recombinant human insulin from Arabidopsis thaliana seeds. Plant Biotechnology Journal, 4(1), 77-85.

64. Conley, A. J., Joensuu, J. J., Jevnikar, A. M., Menassa, R., \& Brandle, J. E. (2009). Optimization of elastin-like polypeptide fusions for expression and purification of recombinant proteins in plants. Biotechnology and Bioengineering, 103(3), 562-573.

65. Linder, M. B., Qiao, M., Laumen, F., Selber, K., Hyytiä, T., Nakari-Setälä, T., \& Penttilä, M. E. (2004). Efficient purification of recombinant proteins using hydrophobins as tags in surfactantbased two-phase systems. Biochemistry, 43(37), 11873-11882.

66. Ma, J. K. C., Drake, P. M. W., \& Christou, P. (2003). The production of recombinant pharmaceutical proteins in plants. Nature Reviews Genetics, 4(10), 794-805.

67. Nuttall, J., Vine, N., Hadlington, J. L., Drake, P., Frigerio, L., \& Ma, J. K. (2002). ER-resident chaperone interactions with recombinant antibodies in transgenic plants. European Journal of Biochemistry, 269(24), 6042-6051.

68. Chatterjee, A., Das, N. C., Raha, S., Maiti, I. B., Shrestha, A., Khan, A., et al. (2017). Enrichment of apoplastic fluid with therapeutic recombinant protein for efficient biofarming. Biotechnology Progress, 33(3), 726-736.

69. Zhang, B., Shanmugaraj, B., \& Daniell, H. (2017). Expression and functional evaluation of biopharmaceuticals made in plant chloroplasts. Current Opinion in Chemical Biology, 38, 17-23. https://doi.org/10.1016/j.cbpa.2017.02.007

70. Streatfield, S. J., \& Howard, J. A. (2003). Plant-based vaccines. International Journal for Parasitology, 33(5-6), 479-493.

71. Mor, T. S., Gómez-Lim, M. A., \& Palmer, K. E. (1998). Perspective: Edible vaccines-A concept coming of age. Trends in Microbiology, 6(11), 449-453.

72. Mason, H. S., Warzecha, H., Mor, T., \& Arntzen, C. J. (2002). Edible plant vaccines: Applications for prophylactic and therapeutic molecular medicine. Trends in Molecular Medicine, 8(7), 324-329.

73. Kusnadi, A. R., Nikolov, Z. L., \& Howard, J. A. (1997). Production of recombinant proteins in transgenic plants: Practical considerations. Biotechnology and Bioengineering, 56(5), 473-484.

74. Jelaska, S., Mihaljevic, S., \& Bauer, N. (2005). Production of biopharmaceuticals, antibodies and edible vaccines in transgenic plants. Current Studies of Biotechnology, 4, 121-127.

75. Penney, C. A., Thomas, D. R., Deen, S. S., \& Walmsley, A. M. (2011). Plant-made vaccines in support of the millennium development goals. Plant Cell Reports, 30(5), 789-798.

76. Rudzik, R., Clancy, R. L., Perey, D. Y. E., Day, R. P., \& Bienenstock, J. (1975). Repopulation with IgA-containing cells of bronchial and intestinal lamina propria after transfer of homologous Peyer's patch and bronchial lymphocytes. The Journal of Immunology, 114(5), 1599-1604.

77. Rescigno, M., Urbano, M., Valzasina, B., Francolini, M., Rotta, G., Bonasio, R., et al. (2001). Dendritic cells express tight junction proteins and penetrate gut epithelial monolayers to sample bacteria. Nature Immunology, 2(4), 361-367.

78. Nochi, T., Takagi, H., Yuki, Y., Yang, L., Masumura, T., Mejima, M., et al. (2007). Rice-based mucosal vaccine as a global strategy for cold-chain-and needle-free vaccination. Proceedings of the National Academy of Sciences USA, 104(26), 10986-10991.

79. Pascual, D. W. (2007). Vaccines are for dinner. Proceedings of the National Academy of Sciences USA, 104(26), 10757-10758.

80. Kurup, V. M., \& Thomas, J. (2020). Edible vaccines: Promises and challenges. Molecular Biotechnology, 62(2), 79-90.

81. Zhou, Z., Gong, S., Yang, Y., Guan, R., Zhou, S., Yao, S., et al. (2015). Expression of Helicobacter pylori urease B on the surface of Bacillus subtilis spores. Journal of Medical Microbiology, 64(1), 104-110. https://doi.org/10.1099/jmm.0.076430-0

82. Tacket, C. O., Mason, H. S., Losonsky, G., Clements, J. D., Levine, M. M., \& Arntzen, C. J. (1998). Immunogenicity in humans of a recombinant bacterial antigen delivered in a transgenic potato. Nature Medicine, 4(5), 607-609. https://doi.org/10.1038/ nm0598-607

83. Tacket, C. O., Pasetti, M. F., Edelman, R., Howard, J. A., \& Streatfield, S. (2004). Immunogenicity of recombinant LT-B delivered orally to humans in transgenic corn. Vaccine, 22(31-32), 43854389. https://doi.org/10.1016/j.vaccine.2004.01.073

84. Yusibov, V., Hooper, D. C., Spitsin, S. V., Fleysh, N., Kean, R. B., Mikheeva, T., et al. (2002). Expression in plants and immunogenicity of plant virus-based experimental rabies vaccine. Vaccine, 20(25-26), 3155-3164. https://doi.org/10.1016/S0264410X(02)00260-8

85. Kapusta, J., Modelska, A., Figlerowicz, M., Pniewski, T., Letellier, M., Lisowa, O., et al. (1999). A plant- derived edible vaccine against hepatitis B virus. The FASEB Journal, 13(13), 1796-1799. https://doi.org/10.1096/fasebj.13.13.1796

86. Thanavala, Y., Mahoney, M., Pal, S., Scott, A., Richter, L., Natarajan, N., et al. (2005). Immunogenicity in humans of an edible vaccine for hepatitis B. Proceedings of the National Academy of Sciences of the United States of America, 102(9), 3378-3382. https://doi.org/10.1073/pnas.0409899102

87. Chichester, J. A., Jones, R. M., Green, B. J., Stow, M., Miao, F., Moonsammy, G., et al. (2012). Safety and immunogenicity of a plant-produced recombinant hemagglutinin-based influenza vaccine (HAI-05) derived from A/Indonesia/05/2005 (H5N1) influenza virus: A phase 1 randomized, double-blind, placebocontrolled, dose760 escalation study in healthy adults. Viruses, 4(11), 3227-3244.

88. Cummings, J. F., Guerrero, M. L., Moon, J. E., Waterman, P., Nielsen, R. K., Jefferson, S., et al. (2014). Safety and immunogenicity of a plant-produced recombinant monomer hemagglutinin-based influenza vaccine derived from influenza A (H1N1) pdm09 virus: A Phase 1 dose-escalation study in healthy adults. Vaccine, 32(19), 2251-2259.

89. McCormick, A. A. (2011). Tobacco derived cancer vaccines for non-Hodgkin's lymphoma: Perspectives and progress. Human vaccines, 7(3), 305-312.

90. Ma, J. K. C., Hikmat, B. Y., Wycoff, K., Vine, N. D., Chargelegue, D., Yu, L., et al. (1998). Characterization of a recombinant plant monoclonal secretory antibody and preventive immunotherapy in humans. Nature Medicine, 4(5), 601-606.

91. Markley, N., Nykiforuk, C., Boothe, J., \& Moloney, M. (2006) Producing proteins using transgenic oilbody-oleosin technology. BioPharm International, 19(6), 34-57. 
92. Shaaltiel, Y., Bartfeld, D., Hashmueli, S., Baum, G., Brill- Almon, E., Galili, G., et al. (2007). Production of glucocerebrosidase with terminal mannose glycans for enzyme replacement therapy of Gaucher's disease using a plant cell system. Plant Biotechnology Journal, 5(5), 579-590.

93. Streatfield, S. J. (2005). Regulatory issues for plant-made pharmaceuticals and vaccines. Expert Review of Vaccines, 4(4), 591-601.

94. Venter, M., \& Botha, F. C. (2010). Synthetic promoter engineering. In E. C. Pua \& M. R. Davey (Eds.), Plant developmental
biology-Biotechnological perspectives (Vol. 2, pp. 393-414). Springer. https://doi.org/10.1007/978-3-642-04670-4_20

Publisher's Note Springer Nature remains neutral with regard to jurisdictional claims in published maps and institutional affiliations. 